\title{
CEREBRAL CIRCULATION AND METABOLISM DURING THIOPENTAL ANESTHESIA AND HYPERVENTILATION IN MAN *
}

\author{
By ELLISON C. PIERCE, JR., † CHRISTIAN J. LAMBERTSEN, STANLEY DEUTSCH, \\ PATRICIA E. CHASE, HARRY W. LINDE, ROBERT D. DRIPPS AND \\ HENRY L. PRICE $\ddagger$
}

\author{
(From the Department of Anesthesiology and Laboratories of Pharmacology, University of \\ Pennsylvania Medical Schools, Philadelphia, Pa.)
}

(Submitted for publication January 29, 1962; accepted May 3, 1962)

Cerebral effects of hyperventilation in normal man, e.g., dizziness, faintness, and impairment of mental function, may be in part related to reduced cerebral oxygen tension $\left(\mathrm{P}_{\mathrm{O}_{2}}\right)$ resulting from hypocapneic cerebral vasoconstriction (1). The prevalent use of controlled respiration during the administration of general anesthetics in the operating room raises questions concerning the extent of hyperventilation which can occur under these conditions and its effect on cerebral $\mathrm{P}_{\mathrm{O}_{2}}$. It is generally recognized that most unconscious patients whose respirations are controlled will unwittingly be hyperventilated by the anesthetist ( 2 , 3 ), and certain anesthetic techniques actually rely upon hyperventilation to achieve their effectiveness (4). Thus the existence of hypocarbia in a substantial fraction of anesthetized patients is extremely likely. However, it has not been shown whether the intrinsic reactivity of cerebral blood vessels to $\mathrm{P}_{\mathrm{CO}_{2}}$ is lost or preserved during general anesthesia. The present study had as its aims: measurement of the effects of thiopental anesthesia on cerebral blood flow (CBF) at normal and reduced arterial $\mathrm{P}_{\mathrm{CO}_{2}}$ and, if hyperventilation did cause cerebral vasoconstriction during anesthesia, determination of the extent to which this could reduce internal jugular venous oxygenation.

\section{METHODS}

Eleven physically normal male volunteers and two female hospital patients were studied. With the exception of one of the patients who was 41 years old, the ages of the subjects ranged from 21 to 27 years. Minor opera-

* Supported in part by Grants H-4589, H-1568, USPHS 2G-215, and USPHS MY-692 from the National Institutes of Health.

$\dagger$ Present address : Department of Anesthesiology, Peter Bent Brigham Hospital, 721 Huntington Avenue, Boston 15 , Mass.

¥ Wellcome Professor of Anesthesiology. tions were performed after completion of the study in the two patients just mentioned. All subjects were studied in the early morning ( 7 a.m.) and had fasted since the previous midnight. Atropine sulfate, $0.4 \mathrm{mg}$, was given intravenously to each before the induction of anesthesia.

Anesthesia was induced with thiopental sodium (2.5 per cent) in doses approximating $200 \mathrm{mg}$, and was thereafter continued by means of intravenous infusions of 0.5 per cent thiopental. Immediately after the induction of anesthesia, $60 \mathrm{mg}$ succinyldicholine was injected intravenously to permit tracheal intubation with a cuffed Magill's tube of appropriate size. Ventilation was controlled by a Bird respirator supplied either with compressed air or with a mixture of 15 per cent $\mathrm{N}_{2} \mathrm{O}$ and 21 per cent $\mathrm{O}_{2}$ in $\mathrm{N}_{2}$. Respiratory paralysis was assured by injecting $d$-tubocurarine intermittently as required. Heparin, 100 $\mathrm{mg}$, was given intravenously before blood sampling began; $100 \mathrm{mg}$ protamine was given intravenously at the end of sampling. Total doses of thiopental and $d$-tubocurarine ranged from 10 to 55 and from 0.7 to $1.3 \mathrm{mg}$ per $\mathrm{kg}$, respectively.

Each study comprised two phases. In one phase, ventilation was adjusted to maintain arterial $\mathbf{P}_{\mathrm{Co}_{2}}$ at a level approximating and not less than $40 \mathrm{~mm} \mathrm{Hg}$; in the other, $\mathrm{P}_{\mathrm{CO}_{2}}$ levels below $20 \mathrm{~mm} \mathrm{Hg}$ were sought. The order of the phases was varied so that in 7 of the 13 normocarbia preceded hypocarbia, whereas the opposite sequence occurred in the remaining subjects. In all instances, 30 or more minutes elapsed between measurements to permit elimination of nitrous oxide.

Measurements were begun after respiratory minute volume had been held constant for a period sufficient to permit $\mathrm{P}_{\mathrm{CO}_{2}}$ to stabilize at the desired level for 10 minutes or longer. Expired gas was sampled through an 18gauge needle inserted into the endotracheal tube, and was analyzed for $\mathrm{CO}_{2}$ using a Liston-Becker analyzer (5). Total respiratory volume was estimated with a Wright anemometer. Respiratory rate was counted from the $\mathrm{P}_{\mathrm{CO}_{2}}$ record. Blood pressures in the femoral arterial and jugular bulb were transduced by Statham strain gauges and were recorded together with the electrocardiogram (lead II) and the fronto-occipital electroencephalogram on a Grass polygraph. Rectal temperature was measured with a calibrated thermistor thermometer. Values reported are averages of readings taken immediately be- 
fore, during, and immediately after measurements of cerebral blood flow (CBF).

In the first four studies CBF was determined over a 10 -minute period, by the continuous sampling modification of the nitrous oxide method (6). The "syringe integration" sampling procedure was first suggested by Schienberg and Stead (7). As the result of the pronounced reduction in $\mathrm{CBF}$ which was encountered in these subjects, it was thought desirable to determine CBF in the remaining subjects over a 25-minute period, with intermittent sampling (8). The first two samples for $\mathrm{N}_{2} \mathrm{O}$ were collected between 0 and 1 , and between 1 and $1.5 \mathrm{~min}$ utes, as described by Kety and Schmidt (8), with additional samples at $3.5,6,15$, and 25 minutes. Cerebral vascular resistance (CVR), cerebral oxygen consumption $\left(\mathrm{CMRO}_{2}\right)$, and cerebral carbon dioxide production $\left(\mathrm{CMRCO}_{2}\right)$ were calculated as previously described (8).

In the first four studies, thiopental concentrations (9), $\mathrm{pH}$, and metabolic gas values were determined on the 10 minute integrated blood samples drawn during the determination of $\mathrm{CBF}$. In the remainder, these measurements were made on three 7-ml samples of arterial and venous blood drawn at a uniform rate during three 30 -second periods: one immediately before, one in the middle, and one immediately after the 25-minute $\mathrm{N}_{2} \mathrm{O}$ measurement period. The samples were combined before analysis. Blood $\mathrm{pH}$ was determined anaerobically in a MacInnesBelcher glass electrode connected to an EIL electrometer. The output of the electrometer was recorded on a Texas Instrument Company Rectiriter; resolution was $0.001 \mathrm{pH}$ units. The glass electrode was enclosed in an electrically shielded air chamber, the temperature of which averaged $36.7^{\circ} \mathrm{C}$ and the extremes differed from this by no more than $0.04^{\circ} \mathrm{C}$. Blood $\mathrm{pH}$ was corrected to the measured rectal temperature with the coefficient 0.0147 per degree C (10), and was also corrected for glycolysis and for effects of whole blood on the glass electrode (11).

Determinations of whole blood metabolic gas composition and $\mathrm{N}_{2} \mathrm{O}$ content were performed manometrically in duplicate as described elsewhere (6). Percentage oxygen saturation of hemoglobin was estimated from the manometrically measured values after corrections for physically dissolved oxygen and, in addition, for hemoconcentration in the determination of the oxygen capacity $(12,13)$. Cerebral venous blood $\mathrm{P}_{\mathrm{O}_{2}}$ was estimated from values for percentage hemoglobin saturation, $\mathrm{pH}$, and body temperature, with the nomogram of Severinghaus (14). Plasma $\mathrm{CO}_{2}$ content was estimated from the whole blood values with the nomogram of Van Slyke and Sendroy. The $\mathrm{P}_{\mathrm{CO}_{2}}$ was calculated from plasma $\mathrm{CO}_{2}$ content, and blood $\mathrm{pH}$ by means of the Henderson-Hasselbalch equation, using the solubility factor and $\mathrm{pK}^{\prime}$ of $\mathrm{CO}_{2}$ in plasma suggested by Severinghaus, Stupfel and Bradley $(11,15)$.

\section{RESULTS}

The principal data obtained in the 13 studies performed are shown in Tables I, II, and III. It will be noted that values for brain circulation and metabolism for Subjects 8 and 9 are not reported. In these studies, a leak occurred in the breathing system used for administering the nitrous oxide mixture.

Thiopental anesthesia. The values for cerebral hemodynamics and metabolism in Table I, observed during anesthesia without hypocapnia, were all grossly and significantly different from corresponding values found in normal conscious young adults: CVR, $1.6 \mathrm{~mm} \mathrm{Hg}$ per $\mathrm{ml}$ per $100 \mathrm{~g}$ per minute; $\mathrm{CBF}, 53 \mathrm{ml}$ per $100 \mathrm{~g}$ per minute; and $\mathrm{CMR}_{\mathrm{O}_{2}}, 3.3 \mathrm{cc}$ per $100 \mathrm{~g}$ per minute $(1,16)$. Anesthesia at an average $\mathrm{P}_{\mathrm{CO}_{2}}$ of $43.8 \mathrm{~mm} \mathrm{Hg}$ and a normal arterial oxygen saturation was associated with an elevated CVR ( $2.9 \mathrm{~mm} \mathrm{Hg}$ per $\mathrm{ml}$ per 100 $\mathrm{g}$ per minute) and with very low values for $\mathrm{CBF}$ (27.6 ml per $100 \mathrm{~g}$ per minute) and $\mathrm{CMR}_{\mathrm{O}_{2}}(1.5$ cc per $100 \mathrm{~g}$ per minute). Under these circumstances, values for internal jugular venous $\mathrm{P}_{\mathrm{O}_{2}}$ and $\mathrm{P}_{\mathrm{CO}_{2}}$, and for the difference in arterial-cerebral venous $\mathrm{O}_{2}$ content were close to normal. The absence of any difference in arterial and internal jugular venous thiopental levels indicates that brain and blood were in approximate equilibrium.

Thiopental anesthesia with hyperventilation. Overventilation to an average arterial $\mathrm{P}_{\mathrm{CO}_{2}}$ of $17.5 \mathrm{~mm} \mathrm{Hg}$ produced no further changes in $\mathrm{CMR}_{\mathrm{O}_{2}}$, but did cause an additional reduction in $\mathrm{CBF}$ to $16.4 \mathrm{ml}$ per $100 \mathrm{~g}$ per minute, and a reduction in internal jugular venous oxygen saturation and $\mathrm{P}_{\mathrm{O}_{2}}$ to 41.6 per cent and $20.6 \mathrm{~mm} \mathrm{Hg}$, respectively, despite an increase in arterial oxygen saturation from 94.8 to 98.8 per cent. There was no change in the "depth" of anesthesia estimated electroencephalographically, although there was a large increase in the concentration of thiopental in the blood during respiratory alkalosis.

No attempt will be made to appraise correlations among changes in physiological variables, since the nature of the experimental design does not lend itself to this type of analysis.

\section{DISCUSSION}

The possibility that the results obtained were influenced by the muscle relaxants used will first be examined. Actions of succinyldicholine on the myoneural junction are terminated within a few minutes by hydrolysis of the molecule, and it is un- 
PIERCE ET AL.

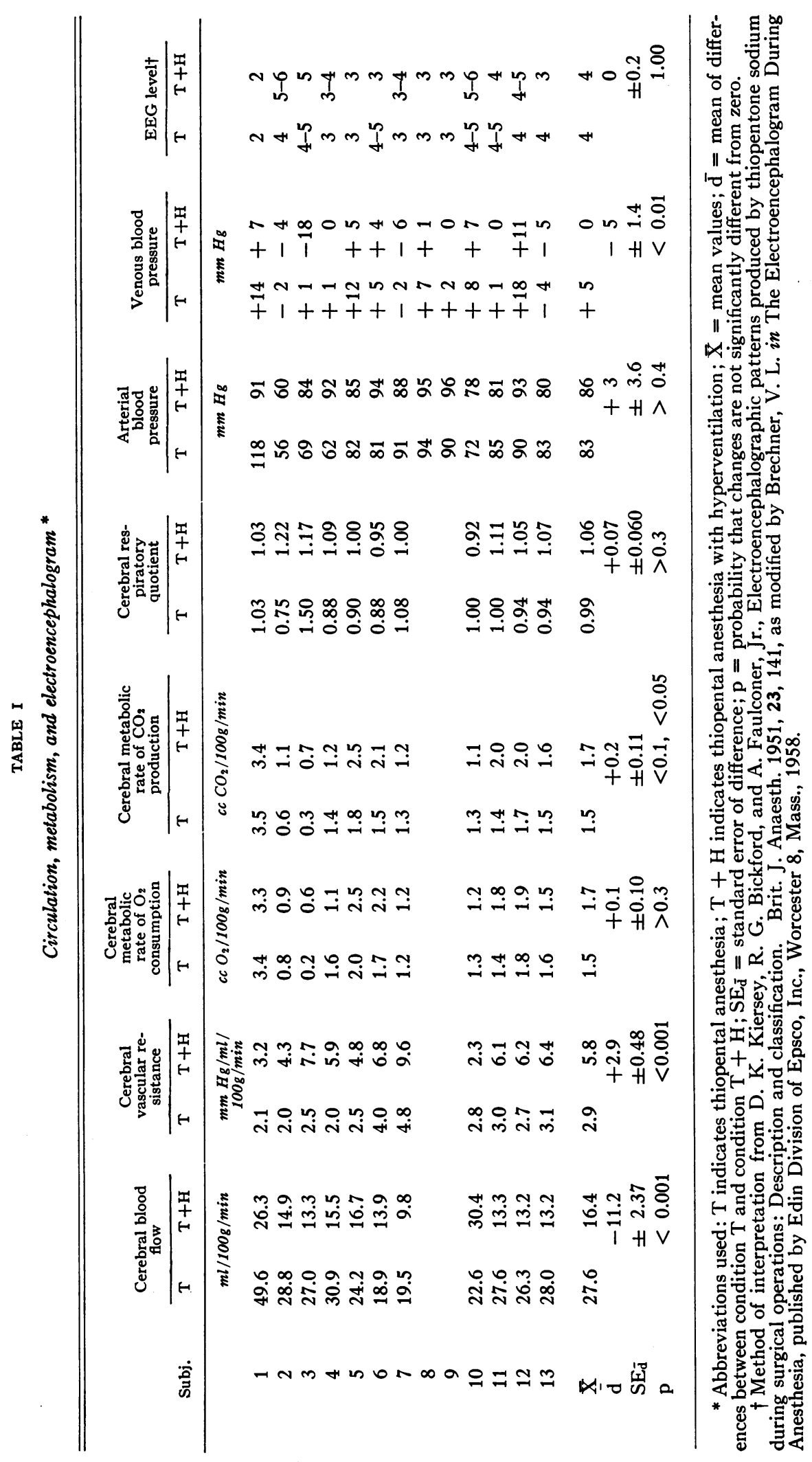


likely that any important pharmacological actions would persist beyond this period. The effects of $d$-tubocurarine are of longer duration, but they do not include any action on the central nervous system sufficient to impair consciousness (17). In the absence of demonstrable central nervous system depression, it appears unlikely that $d$-tubocurarine would alter cerebral metabolic rate. Earlier studies from this laboratory (18) have shown that thiopental alone depresses cerebral metabolic rate; after doses roughly half those used in the present study, cerebral oxygen consumption averaged 2.1 $\mathrm{ml}$ per $100 \mathrm{~g}$ per minute, a 36 per cent reduction from normal values. The reduction found in the present study ( 55 per cent) is that which would be expected if the dose-response curve followed the exponential (logarithm of the dose: effect) relation so frequently encountered in biological systems. Although these arguments do not prove that $d$-tubocurarine fails to alter $\mathrm{CMR}_{\mathrm{O}_{2}}$, they do appear to minimize the importance of such an action, if it exists. Despite its apparent failure to depress central nervous system function to any large degree, there is evidence that vascular smooth

TABLE II

Arterial and internal jugular venous blood parameters *

\begin{tabular}{|c|c|c|c|c|c|c|c|c|c|c|c|c|c|c|}
\hline \multirow[b]{2}{*}{ Subj. } & \multicolumn{2}{|c|}{$\mathrm{O}_{2}$ content } & \multicolumn{2}{|c|}{$\mathrm{O}_{2}$ capacity } & \multicolumn{4}{|c|}{$\begin{array}{l}\text { A. Arterial parameters } \\
\text { Hb saturation }\end{array}$} & \multicolumn{2}{|r|}{$\mathrm{pH}$} & \multicolumn{2}{|c|}{$\mathrm{PcO}_{2}$} & \multicolumn{2}{|c|}{ Thiopental } \\
\hline & $T$ & $\mathrm{~T}+\mathrm{H}$ & $T$ & $\mathbf{T}+\mathrm{H}$ & $T$ & $\mathrm{~T}+\mathrm{H}$ & $\mathbf{T}$ & $\mathrm{T}+\mathrm{H}$ & $\mathbf{T}$ & $\mathrm{T}+\mathrm{H}$ & $T$ & $\mathrm{~T}+\mathrm{H}$ & $T$ & $\mathrm{~T}+\mathrm{H}$ \\
\hline & \multicolumn{2}{|c|}{$m l / 100 m l$} & \multicolumn{2}{|c|}{$\mathrm{ml} / 100 \mathrm{ml}$} & \multicolumn{2}{|r|}{$\%$} & \multicolumn{2}{|c|}{$\mathrm{ml} / 100 \mathrm{ml}$} & \multicolumn{2}{|c|}{ units } & \multicolumn{2}{|c|}{$m m \mathrm{Hg}$} & \multicolumn{2}{|r|}{$m g / L$} \\
\hline 1 & 17.1 & 17.8 & 19.3 & 19.0 & 91.8 & 96.7 & 47.9 & 31.3 & 7.35 & 7.52 & 43.9 & 19.7 & 7 & 11 \\
\hline 2 & 14.0 & 15.8 & 16.0 & 16.5 & 91.4 & 98.7 & 50.7 & 33.7 & 7.29 & 7.63 & 50.4 & 16.1 & 37 & 54 \\
\hline 3 & 12.7 & 14.0 & 14.7 & 14.8 & 90.6 & 97.8 & 48.3 & 36.6 & 7.26 & 7.53 & 51.4 & 21.3 & 24 & 30 \\
\hline 4 & 19.1 & 21.0 & 21.1 & 21.9 & 89.6 & 95.0 & 46.0 & 33.8 & 7.32 & 7.57 & 45.4 & 19.7 & 23 & 30 \\
\hline 5 & 17.3 & 19.0 & 17.0 & 18.3 & 99.4 & $100+$ & 47.9 & 34.5 & 7.40 & 7.65 & 38.2 & 16.1 & 22 & 31 \\
\hline 6 & 18.9 & 21.1 & 19.8 & 20.4 & 94.5 & $100+$ & 45.9 & 35.5 & 7.37 & 7.64 & 40.3 & 17.6 & 25 & 34 \\
\hline 7 & 19.8 & 20.9 & 20.1 & 20.5 & 97.0 & $100+$ & 45.9 & 29.8 & 7.37 & 7.66 & 40.6 & 14.2 & 32 & 40 \\
\hline 8 & 18.4 & 19.3 & 19.2 & 18.5 & 94.8 & $100+$ & 47.0 & 37.2 & 7.35 & 7.62 & 43.1 & 18.7 & 21 & 33 \\
\hline 9 & 18.1 & 19.5 & 19.5 & 19.4 & 91.8 & 98.5 & 49.4 & 32.0 & 7.30 & 7.59 & 50.8 & 17.7 & 28 & 43 \\
\hline 10 & 19.1 & 18.5 & 19.1 & 18.2 & 98.4 & $100+$ & 48.6 & 36.5 & 7.41 & 7.68 & 38.7 & 16.4 & 36 & 45 \\
\hline 11 & 18.8 & 18.9 & 19.0 & 18.8 & 97.4 & 98.9 & 51.3 & 35.7 & 7.38 & 7.69 & 43.7 & 15.5 & 25 & 35 \\
\hline 12 & 16.9 & 17.0 & 17.0 & 17.0 & 97.6 & 98.2 & 49.8 & 36.6 & 7.38 & 7.67 & 40.6 & 16.0 & 28 & 43 \\
\hline 13 & 18.0 & 17.9 & 18.1 & 17.3 & 97.8 & $100+$ & 51.2 & 37.9 & 7.39 & 7.64 & 41.8 & 18.0 & 22 & 32 \\
\hline $\begin{array}{l}\overline{\mathbf{X}} \\
\overline{\mathbf{d}} \\
\mathrm{SE}_{\bar{d}} \\
\mathbf{p}\end{array}$ & 17.6 & $\begin{aligned} & 18.5 \\
+ & 1.0 \\
\pm & 0.24 \\
< & 0.01\end{aligned}$ & 18.5 & $\begin{aligned} & 18.5 \\
+ & 0.1 \\
\pm & 0.17 \\
> & 0.5\end{aligned}$ & 94.8 & $\begin{aligned} & 98.8 \\
+ & 4.0 \\
\pm & 0.69 \\
> & 0.001\end{aligned}$ & 48.5 & $\begin{array}{c}34.7 \\
-13.8 \\
\pm 0.71 \\
<0.001\end{array}$ & 7.35 & $\begin{array}{c}7.62 \\
+0.27 \\
\pm 0.011 \\
<0.001\end{array}$ & 43.8 & $\begin{aligned} & 17.5 \\
- & 26.3 \\
\pm & 1.11 \\
< & 0.001\end{aligned}$ & 25 & $\begin{array}{l}35 \\
+10 \\
\pm 1.04 \\
<0.001\end{array}$ \\
\hline \multicolumn{15}{|c|}{ B. Internal jugular venous parameters } \\
\hline & \multicolumn{2}{|c|}{$\mathrm{O}_{2}$ content } & \multicolumn{2}{|c|}{ Hb saturation } & \multicolumn{2}{|r|}{$\mathrm{Po}_{2}$} & \multicolumn{2}{|c|}{$\mathrm{CO}_{2}$ content } & \multicolumn{2}{|c|}{$\mathbf{p H}$} & \multicolumn{2}{|c|}{$\mathrm{PcO}_{2}$} & \multicolumn{2}{|c|}{ Thipoental } \\
\hline \multirow[t]{2}{*}{ Subj. } & $T$ & $\mathbf{T}+\mathrm{H}$ & $\mathbf{T}$ & $\mathrm{T}+\mathrm{H}$ & $T$ & $\mathrm{~T}+\mathrm{H}$ & $\mathbf{T}$ & $\mathbf{T}+\mathbf{H}$ & $\mathrm{T}$ & $\mathrm{T}+\mathrm{H}$ & $\mathbf{T}$ & $\mathrm{T}+\mathrm{H}$ & $T$ & $\mathrm{~T}+\mathrm{H}$ \\
\hline & \multicolumn{2}{|c|}{$m l / 100 m l$} & & $\%$ & & $m \mathrm{Hg}$ & $m l /$ & $100 m l$ & & enits & & $m \boldsymbol{H g}$ & & $m g / L$ \\
\hline 1 & 10.2 & 5.1 & 54.9 & 27.6 & 33.2 & 17.5 & 55.0 & 44.3 & 7.29 & 7.40 & 55.7 & 35.2 & 8 & 13 \\
\hline 2 & 11.4 & 9.9 & 74.8 & 62.8 & 45.7 & 27.9 & 52.9 & 40.9 & 7.27 & 7.53 & 54.4 & 23.7 & 30 & 51 \\
\hline 3 & 11.9 & 9.8 & 84.8 & 69.8 & 61.2 & 33.5 & 49.4 & 41.8 & 7.24 & 7.47 & 54.3 & 27.8 & 22 & 27 \\
\hline 4 & 13.8 & 13.8 & 64.9 & 62.6 & 37.1 & 28.9 & 50.6 & 41.3 & 7.28 & 7.50 & 53.3 & 27.5 & 21 & 26 \\
\hline 5 & 9.1 & 4.3 & 52.9 & 23.5 & 28.8 & 12.6 & 55.5 & 49.4 & 7.33 & 7.51 & 50.1 & 30.7 & 21 & 31 \\
\hline 6 & 9.9 & 5.5 & 49.5 & 27.0 & 29.0 & 15.0 & 53.8 & 50.3 & 7.32 & 7.51 & 51.9 & 32.4 & 23 & 32 \\
\hline 7 & 13.4 & 9.2 & 66.2 & 44.4 & 37.3 & 21.1 & 52.8 & 42.0 & 7.32 & 7.53 & 51.0 & 26.1 & 31 & 39 \\
\hline 8 & 13.2 & 5.6 & 68.2 & 29.7 & 39.2 & 16.0 & 52.4 & 50.8 & 7.31 & 7.50 & 51.6 & 32.6 & 21 & 33 \\
\hline 9 & 12.7 & 6.3 & 64.6 & 32.0 & 33.5 & 18.7 & 54.4 & 45.3 & 7.24 & 7.47 & 61.9 & 31.1 & 28 & 40 \\
\hline 10 & 13.5 & 14.5 & 70.2 & 79.1 & 37.1 & 34.8 & 54.4 & 40.1 & 7.36 & 7.62 & 47.5 & 20.0 & 34 & 45 \\
\hline 11 & 13.6 & 5.2 & 71.1 & 27.7 & 38.0 & 14.8 & 56.3 & 50.4 & 7.34 & 7.53 & 51.7 & 30.5 & 24 & 29 \\
\hline 12 & 10.0 & 2.8 & 58.2 & 16.5 & 29.3 & 9.3 & 56.3 & 51.5 & 7.34 & 7.52 & 50.4 & 30.4 & 33 & 42 \\
\hline 13 & 12.3 & 6.6 & 67.4 & 37.6 & 35.2 & 18.3 & 56.6 & 49.7 & 7.35 & 7.51 & 50.7 & 30.8 & 22 & 31 \\
\hline $\begin{array}{l}X \\
\bar{d} \\
S E_{\bar{d}} \\
p\end{array}$ & 11.9 & $\begin{array}{ll} & 7.6 \\
- & 4.3 \\
\pm & 0.81 \\
< & 0.001\end{array}$ & 65.2 & $\begin{array}{c}41.6 \\
-23.6 \\
\pm \quad 4.26 \\
<0.001\end{array}$ & 37.3 & $\begin{aligned} & 20.6 \\
- & 16.6 \\
\pm & 1.81 \\
< & 0.001\end{aligned}$ & 53.9 & $\begin{array}{c}\quad 46.0 \\
-7.9 \\
\pm 1.00 \\
<0.001\end{array}$ & 7.31 & $\begin{array}{l}7.51 \\
-0.20 \\
\pm 0.011 \\
<0.001\end{array}$ & 52.7 & $\begin{array}{c}29.1 \\
+23.5 \\
\pm 1.21 \\
<0.001\end{array}$ & 24 & $\begin{array}{l}\quad 34 \\
+9 \\
\pm 1.2 \\
<0.001\end{array}$ \\
\hline
\end{tabular}

* Abbreviations as in Table I. 


\begin{tabular}{|c|c|c|c|c|c|c|}
\hline \multirow[b]{2}{*}{ Subj. } & \multicolumn{2}{|r|}{$\dot{V}_{E}$} & \multicolumn{2}{|c|}{ VT } & \multicolumn{2}{|r|}{$\mathbf{f}$} \\
\hline & $T$ & $\mathrm{~T}+\mathrm{H}$ & $T$ & $\mathrm{~T}+\mathrm{H}$ & $T$ & $\mathrm{~T}+\mathrm{H}$ \\
\hline & \multicolumn{2}{|c|}{$L / \min , A T P D$} & \multicolumn{2}{|c|}{$L$} & \multicolumn{2}{|c|}{ breaths/min } \\
\hline 1 & 7.80 & 16.20 & 0.622 & 1.209 & 12.6 & 13.4 \\
\hline 2 & 2.15 & 13.23 & 0.537 & 0.917 & 4.0 & 14.5 \\
\hline 3 & 3.21 & 9.52 & 0.558 & 0.912 & 5.8 & 10.4 \\
\hline 4 & 4.99 & 17.39 & 0.763 & 1.121 & 6.5 & 15.5 \\
\hline 5 & 6.47 & 17.43 & 0.729 & 1.363 & 8.9 & 12.8 \\
\hline 6 & 7.23 & 19.10 & 0.852 & 1.209 & 8.5 & 15.8 \\
\hline 7 & 6.41 & 24.49 & 0.835 & 1.316 & 7.7 & 18.6 \\
\hline 8 & 5.32 & 12.78 & 0.795 & 1.170 & 6.7 & 11.2 \\
\hline 9 & 7.67 & 15.31 & 1.565 & 1.597 & 4.9 & 9.6 \\
\hline 10 & 4.05 & 12.30 & 0.620 & 1.140 & 6.5 & 10.8 \\
\hline 11 & 5.14 & 16.76 & 0.751 & 1.262 & 6.8 & 13.3 \\
\hline 12 & 2.78 & 12.20 & 0.651 & 1.058 & 4.3 & 11.6 \\
\hline 13 & 3.69 & 16.43 & 0.661 & 1.559 & 5.6 & 10.5 \\
\hline$\overline{\mathbf{x}}$ & 5.15 & 15.63 & 0.765 & 1.218 & 6.8 & 12.9 \\
\hline$\overline{\mathrm{d}}$ & & +10.48 & & +0.453 & & +6.1 \\
\hline $\mathrm{SE}_{\overline{\mathrm{d}}}$ & & \pm 0.86 & & \pm 0.0552 & & \pm 0.79 \\
\hline p & & $<0.001$ & & $<0.001$ & & $<0.001$ \\
\hline
\end{tabular}

*Abbreviations same as in Table $\mathrm{I}$.

muscle is affected by curare. Direct actions on blood vessels, however, appear only at high concentrations of curare (as after intra-arterial injection) and are opposite in direction $(19,20)$ to the changes observed in the present study. An influence of curare on responses to hyperventilation is believed unlikely, since the results were independent of the order in which the studies were carried out; yet when hyperventilation preceded normal ventilation, the dose of curare given prior to the period of study was roughly one-half that administered when the reverse order of procedure was employed.

Although administration of thiopental and other respiratory depressant drugs in man during natural breathing has been found to cause decreased oxygen utilization, blood flow in the brain under these circumstances has been found to increase, to remain unchanged, or to decrease relatively less than oxygen consumption (18, 21-25). Since cerebral vasodilatation is an expected accompaniment of the arterial hypercapnia secondarily induced by the respiratory depression, the direct actions of a depressant drug upon cerebral vessels may be masked or even reversed by the powerful indirect influence of changes in arterial $\mathrm{P}_{\mathrm{CO}_{2}}(26$ 28). The findings of the present study will be discussed first from the standpoint of thiopental effects which appear to be unrelated to changes in $\mathrm{P}_{\mathrm{CO}_{2}}$, and second with regard to effects of $\mathrm{P}_{\mathrm{CO}_{2}}$ in the presence of thiopental. In each instance the findings will be referred to existing information concerning the brain metabolism and hemodynamics of resting, conscious subjects $(26,27)$.

Thiopental anesthesia. The rate of brain oxygen consumption in our anesthetized subjects, who were maintained close to normal arterial $\mathrm{P}_{\mathbf{C O}_{2}}$, represents a reduction of approximately 55 per cent from that observed in conscious, normocapneic subjects $(16,26,27)$. This depression of metabolism is as low as any previously found during various types of unconsciousness resulting from drug administration $(16,26,27)$. In the present study, the depth of anesthesia as determined from clinical signs, EEG level, and blood thiopental content, was profound. Since there is normally a close relation between depth of anesthesia and depression of brain metabolism $(26,27,29)$, the finding of a low $\mathrm{CMR}_{\mathrm{O}_{2}}$ had been anticipated. Presumably, a greater depth of anesthesia would have been associated with still further depression of $\mathrm{CMR}_{\mathbf{O}_{2}}$. Despite this degree of metabolic depression, the absence of change in $R Q$ suggests that brain metabolism was not qualitatively altered.

Brain blood flow was also markedly reduced by thiopental administration to about 50 per cent of normal levels. This finding was not wholly expected, especially in view of previous suggestions that narcotic agents depress cerebral vascular tone (16) and the discrepant findings of previous studies of the effects of barbiturate anesthesia on CBF cited above. The reduction of $\mathrm{CBF}$ in this study could be ascribed only in small part to reduced arteriovenous perfusion pressure; its major cause was a large increase in CVR.

The observed high cerebral vascular resistance could have been due to any of a number of factors, ranging from an action of thiopental upon the smooth muscle of brain vessels to an effect somehow related to depression of brain oxygen metabolism. Thiopental has in fact been demonstrated to exert constrictor action upon the smooth muscle of isolated strips of rabbit aorta, and to enhance the vasoconstrictor activity of norepinephrine (30), but in concentrations greater than those used in the present study. Since the direct actions of drugs upon brain vessels do not appear to be qualitatively different from those upon other vascular smooth muscle, a constrictor effect of thiopental upon cerebral vessels remains as a possible 
contributor to the high CVR observed in the anesthetized subjects.

For many years it has been assumed that the blood flow through the brain is adjusted to the local metabolic demands of brain tissue. Such intrinsic adjustments are usually related to local alterations of $\mathrm{P}_{\mathrm{CO}_{2}}$ secondary to changes in the rate of carbon dioxide production or oxygen utilization $(16,26,27,31,32)$. Evidence for an influence of CNS activity upon brain blood flow does exist in the form of enhanced rate of blood flow in the visual cortex during photic stimulation of the retina $(33,34)$ and the increased brain blood flow which accompanies administration of convulsant drugs $(16,26,27,31,32)$. It has been pointed out elsewhere, however, that the association of increased brain blood flow and rate of $\mathrm{CMR}_{\mathrm{CO}_{2}}$ may not be real, and that the basis for adjustment of blood flow to neuronal activity need not be either rise in central $\mathrm{P}_{\mathrm{CO}_{2}}$ or fall in central $\mathrm{P}_{\mathrm{O}_{2}}$ (35). Evidence offered for this opposite view is that elevation of central $\mathrm{P}_{\mathrm{CO}_{2}}$, unaccompanied by concurrent arterial hypercapnia, does not increase blood flow through the brain (35-37).

In the present study the association of thiopental-induced depression of cerebral metabolism and the concomitant decrease in blood flow are not related to altered central $\mathrm{P}_{\mathbf{C O}_{2}}$ since, in spite of the gross reduction of $\mathrm{CO}_{2}$ production, the observed values for arterial and jugular venous $\mathrm{P}_{\mathrm{CO}_{2}}$ are not reduced below normal.

Thiopental anesthesia and hyperventilation. The absence of a further change in $\mathrm{CMR}_{\mathrm{O}_{2}}$ during hyperventilation is consistent with numerous observations that alteration in $\mathrm{P}_{\mathbf{C O}_{2}}$ does not affect cerebral $\mathrm{O}_{2}$ uptake $(26,27)$. This, together with the lack of change in EEG level, suggests that cerebral activity was similar in the two experimental phases. Since both methods are gross, it cannot be said that a particular region of the brain was unaffected, but only that the over-all effect was negligible. During hyperventilation $\mathrm{CBF}$ was decreased from an already reduced level to a value only 30 per cent of normal. This reduction of $\mathrm{CBF}$ in response to hyperventilation is of the same magnitude per millimeter $\mathrm{Hg}$ decrease in arterial $\mathrm{P}_{\mathrm{CO}_{2}}$ as that found by Kety and Schmidt in normal young men (1), indicating that deep thiopental anesthesia does not interfere with cerebral vascular reactivity to hypocapnia. Whether this is also true of other general anesthetic agents cannot be answered at present.

It is perhaps surprising that hyperventilation failed to increase anesthetic (EEG) "depth" in the subjects studied, particularly since concentrations of thiopental in blood were significantly elevated during hypocarbia. However, since thiopental is a weak acid with a $\mathrm{pK}$ nearly equal to normal arterial $\mathrm{pH}$, an increase in $\mathrm{pH}$ of $0.3 \mathrm{U}$ can be estimated to reduce the fraction of barbiturate in the acid (active) form by about one-third. Thus, the concentration of pharmacologically active drug presented to the nervous system was essentially the same during hyperventilation and normal ventilation.

The extremely low oxygen content of internal jugular venous blood drawn during hyperventilation raised the question of the adequacy of cerebral oxygenation. The reduction in $\mathrm{CBF}$ without further change in $\mathrm{CMR}_{\mathrm{O}_{2}}$ during hyperventilation under anesthesia resulted in a nearly twofold increase in arterial-cerebral venous $\mathrm{O}_{2}$ content difference, and consequently in marked reductions in internal jugular $\mathrm{P}_{\mathrm{O}_{2}}$ and oxygen saturation, despite the increase in arterial saturation. Certainly a reduction in oxygenation of unanesthetized subjects results in a decline in brain oxygen consumption (38). It has been suggested that in unanesthetized subjects unconsciousness may develop when the cerebral venous $\mathrm{P}_{\mathbf{O}_{2}}$ falls to levels below 15 to $20 \mathrm{~mm} \mathrm{Hg}(35,39,40)$ and that even under normal conditions the cerebral cortex verges upon insufficiency (41). There are steep diffusion gradients from capillaries to cerebral neurons, and in regions between capillaries small reductions in capillary $\mathrm{P}_{\mathrm{O}_{2}}$ might reduce the availability of oxygen below necessary levels. A great deal has been written on this subject, almost all of which is speculation. It is undoubtedly true that hyperventilation can cause cerebral vasoconstriction, can severely reduce cerebral $\mathrm{P}_{\mathrm{O}_{2}}$ [as measured by an oxygen electrode inserted in the cerebral cortex (42), or by measurements of blood draining the brain (38)], and can reduce psychomotor function and impair consciousness (43). In anesthetized men, hyperventilation appears by clinical criteria to deepen the level of anesthesia (4). But it remains uncertain whether reduced $\mathrm{P}_{\mathrm{O}_{2}}$ alone causes these changes in cerebral function. In the light of present knowledge, these changes might 
equally well result from the removal of tonic facilitatory actions of $\mathrm{CO}_{2}$, or from concurrent effects of lowered oxygen and carbon dioxide tensions.

\section{SUM MARY AND CONCLUSIONS}

1. Administration of large doses of thiopental to normal subjects caused significant and nearly proportional reductions in cerebral metabolic rate and cerebral blood flow; cerebral vascular resistance was increased.

2. Hyperventilation during anesthesia produced no further reduction in oxygen consumption, although it decreased blood flow to extremely low levels.

3. These results are interpreted to mean that the reactivity of cerebral blood vessels to carbon dioxide is preserved even at profound levels of thiopental anesthesia.

\section{ACKNOWLEDGMENT}

The authors express their appreciation for the excellent and patient technical assistance of $\mathrm{E}$. Jones and $\mathrm{B}$. Hanley.

\section{REFERENCES}

1. Kety, S. S., and Schmidt, C. F. The effects of active and passive hyperventilation on cerebral blood flow, cerebral oxygen consumption, cardiac output, and blood pressure of normal young men. J. clin. Invest. 1946, 25, 107.

2. Clutton-Brock, J. Cerebral effects of overventilation. Brit. J. Anaesth. 1957, 29, 111.

3. Stephen, C. R., Fabian, L. W., Dent, S., and Bourgeois-Gavardin, M. Hypoventilation and hyperventilation during anesthesia for thoracic surgery. J. Amer. med. Ass. 1958, 166, 1678.

4. Robinson, J. S., and Gray, T. C. Observations on the cerebral effects of passive hyperventilation. Brit. J. Anaesth. 1961, 33, 62.

5. Collier, C. R., Affeldt, J. E., and Farr, A. F. Continuous rapid infrared carbon dioxide analysis: Fractional sampling and accuracy in determining alveolar $\mathrm{CO}_{2}$. J. Lab. clin. Med. 1955, 45, 526.

6. Lambertsen, C. J., Owen, S. G., Wendel, H., Stroud, M. W., Lurie, A. A., Lochner, W., and Clark, G. F. Respiratory and cerebral circulatory control during exercise at .21 and 2.0 atmospheres inspired $\mathrm{Po}_{2}$. J. appl. Physiol. 1959, 14, 966.

7. Scheinberg, P., and Stead, E. A., Jr. The cerebral blood flow in male subjects as measured by the nitrous oxide technique. Normal values for blood flow, oxygen utilization, glucose utilization, and peripheral resistance, with observations on the effect of tilting and anxiety. J. clin. Invest. 1949, 28, 1163.
8. Kety, S. S., and Schmidt, C. F. Determination of cerebral blood flow in man by use of nitrous oxide in low concentrations. Amer. J. Physiol. 1945, $143,53$.

9. Brodie, B. B., Mark, L. C., Papper, E. M., Lief, P. A., Bernstein, E., and Rovenstine, E. A. The fate of thiopental in man and a method for its estimation in biological material. J. Pharmacol. exp. Ther. 1950, 98, 85.

10. Rosenthal, T. B. The effect of temperature on the $\mathrm{pH}$ of blood and plasma in vitro. J. biol. Chem. 1948, 173, 25.

11. Severinghaus, J. W., Stupfel, M., and Bradley, A. F. Accuracy of blood $\mathrm{pH}$ and $\mathrm{PCO}_{2}$ determinations. J. appl. Physiol. 1956, 9, 189.

12. Sendroy, J., Jr., Dillon, R. T., and Van Slyke, D. D. Studies of gas and electrolyte equilibria in blood. XIX. The solubility and physical state of uncombined oxygen in blood. J. biol. Chem. 1934, 105, 597.

13. Roughton, F. J. W., Darling, R. C., and Root, W. S. Factors affecting the determination of oxygen capacity, content and pressure in human arterial blood. Amer. J. Physiol. 1944, 142, 708.

14. Severinghaus, J. W. Oxyhemoglobin dissociation curve correction for temperature and $\mathrm{pH}$ variation in human blood. J. appl. Physiol. 1958, 12, 485.

15. Severinghaus, J. W., Stupfel, M., and Bradley, A. F. Variations of serum carbonic acid $\mathrm{pK}^{\prime}$ with $\mathrm{pH}$ and temperature. J. appl. Physiol. 1956, 9, 197.

16. Schmidt, C. F. The Cerebral Circulation in Health and Disease. Springfield, Ill., Thomas, 1950.

17. Smith, S. M., Brown, H. O., Toman, J. E. P., and Goodman, L. S. The lack of cerebral effects of d-tubocurarine. Anesthesiology 1947, 8, 1.

18. Wechsler, R. L., Dripps, R. D., and Kety, S. S. Blood flow and oxygen consumption of the human brain during anesthesia produced by thiopental. Anesthesiology 1951, 12, 308.

19. Bean, J. W., and Elwell, L. H. Vascular response in mammalian skeletal muscle to d-tubocurarine. Amer. J. Physiol. 1951, 164, 734.

20. Elwell, L. H., and Bean, J. W. Intestinal blood flow in curarization. Amer. J. Physiol. 1953, 174, 185.

21. Himwich, W. A., Homburger, E., Maresca, R., and Himwich, H. E. Brain metabolism in man: Unanesthetized and in pentothal narcosis. Amer. J. Psychiat. 1947, 103, 689.

22. Schieve, J. F., and Wilson, W. P. The influence of age, anesthesia and cerebral arteriosclerosis on cerebral vascular activity to $\mathrm{CO}_{2}$. Amer. J. Med. 1953, 15, 171.

23. Fazekas, J. F, and Bessman, A. N. Coma mechanisms. Amer. J. Med. 1953, 15, 804.

24. Battey, L. L., Heyman, A., and Patterson, J. L., Jr. Effects of ethyl alcohol on cerebral blood flow and metabolism. J. Amer. Med. Ass. 1953, 152, 6.

25. Moyer, J. H., Pontius, R., Morris, G., and Hershberger, $R$. Effect of morphine and n-allylnor- 
morphine on cerebral hemodynamics and oxygen metabolism. Circulation 1957, 15, 379.

26. Sokoloff, L. The action of drugs on the cerebral circulation. Pharmacol. Rev. 1959, 11, 1.

27. Lassen, N. A. Cerebral blood flow and oxygen consumption in man. Physiol. Rev. 1959, 39, 183.

28. Price, H. L. General anesthesia and circulatory homeostasis. Physiol. Rev. 1960, 40, 187.

29. Kety, S. S. The physiology of the human cerebral circulation. Anesthesiology 1949, 10, 610.

30. Price, M. L., and Price, H. L. Effects of general anesthetics on contractile responses of rabbit aortic strips. Anesthesiology 1962, 23, 16.

31. Meyer, J. S., and Gotoh, F. Interaction of cerebral hemodynamics and metabolism. Neurology 1961, 11, 46.

32. Gotoh, F., Tazaki, Y., and Meyer, J. S. Transport of gases through brain and their extravascular vasomotor action. Exp. Neur. 1961, 4, 48.

33. Schmidt, C. F., and Hendrix, J. P. The action of chemical substances on cerebral blood-vessels. Ass. Res. nerv. Dis. Proc. 1938, 18, 229.

34. Sokoloff, L., and Kety, S. S. Regulation of cerebral circulation. Physiol. Rev. 1960, 40, suppl. 4, 38.

35. Lambertsen, C. J. in Medical Physiology, P. Bard, Ed. St. Louis, Mosby, 1961, pp. 650-654.

36. Turner, J. E., Lambertsen, C. J., Owen, S. G., Wendel, $H$., and Chiodi, H. Effects of .08 and .8 atmos- pheres of inspired $\mathrm{pO}_{2}$ upon cerebral hemodynamics at a "constant" alveolar $\mathrm{pCO}_{2}$ of $43 \mathrm{~mm}$. Hg. Fed. Proc. 1957, 16, 130.

37. Lambertsen, C. J., Kough, R. H., Cooper, D. Y., Emmel, G. L., Loeschcke, H. H., and Schmidt, C. F. Oxygen toxicity; effects in man of oxygen inhalation at 1 and 3.5 atmospheres upon blood gas transport, cerebral circulation and cerebral metabolism. J. appl. Physiol. 1953, 5, 471.

38. Lambertsen, C. J. Oxygen, carbon dioxide and helium in Pharmacology in Modern Medicine, V. A. Drill, Ed. New York, McGraw-Hill, 1958.

39. Lennox, W. G., Gibbs, F. A., and Gibbs, E. L. Relationship of unconsciousness to cerebral blood flow and to anoxemia. AMA Arch. Neurol. Psychiat. 1935, 34, 1001.

40. Opitz, E., and Schneider, M. Uber die Sauerstoffversorgung des Gehirns und den Mechanismus von Mangelwirkung. Ergebn. Physiol. 1950, 46, 126.

41. Davies, P. W., and Bronk, D. W. Oxygen tensions in mammalian brain. Fed. Proc. 1957, 16, 689.

42. Sugioka, K., and Davis, D. A. Hyperventilation with oxygen-A possible cause of cerebral hypoxia. Anesthesiology 1960, 21, 135.

43. Balke, B., Ellis, J. P., Jr., and Wells, J. G. Adaptive responses to hyperventilation. J. appl. Physiol. 1958, 12, 269. 